\title{
Fucoxanthin pigment markers of marine phytoplankton analysed by HPLC and HPTLC
}

\author{
Simon W. Wright ${ }^{1} \&$ S. W. Jeffrey ${ }^{2}$ \\ ${ }^{1}$ Antarctic Division, Department of Science, Channel Highway, Kingston, Tasmania 7150 , Australia \\ ${ }^{2}$ CSIRO Division of Fisheries Research, Marine Laboratories, GPO Box 1538, Hobart, Tasmania 7001, Australia
}

\begin{abstract}
High-performance thin-layer chromatography (HPTLC) and high-performance liquid chromatography (HPLC) were used to separate fucoxanthin, $19^{\prime}$-hexanoyloxyfucoxanthin and a $19^{\prime}$ butanoyloxyfucoxanthin-like pigment from algal cultures. Pavlova lutheri (Prymnesiophyceae) contained fucoxanthin only, whereas Emiliania huxleyi, Phaeocystis pouchetii (Prymnesiophyceae) and Pelagococcus subviridis (Chrysophyceae) contained all 3 fucoxanthin pigments in widely different proportions. The 3 pigments, which were also found in phytoplankton samples from Antarctic waters, may provide useful markers of phytoplankton in field samples. The HPTLC method provides a rapid screening technique for fucoxanthin pigments, complementing the more powerful but time-consuming HPLC
\end{abstract}

\section{INTRODUCTION}

Knowledge of the range of photosynthetic pigments in a phytoplankton sample can indicate the algal classes present in phytoplankton populations, information not available from simple chlorophyll and 'pheopigment' analyses (Jeffrey 1974). For example, thin-layer chromatography (TLC) unexpectedly revealed significant quantities of chlorophyll $b$ (green algae) in the North Pacific Ocean (Jeffrey 1976), and fucoxanthin (diatoms, prymnesiophytes) was found to be the dominant carotenoid compared to the insignificant peridinin (photosynthetic dinoflagellates) in Australian coastal and oceanic phytoplankton (Jeffrey \& Hallegraeff 1980, Hallegraeff 1981, Hallegraeff \& Jeffrey 1984, Jeffrey \& Hallegraeff 1987). TLC (Jeffrey 1981) has also allowed separation and identification of many types of chlorophyll degradation products in phytoplankton field samples (Hallegraeff \& Jeffrey 1985).

The application of high-performance liquid chromatography (HPLC) in phytoplankton studies (e.g. Mantoura \& Llewellyn 1983, Wright \& Shearer 1984) has extended the range of pigment separations, making available more 'marker' pigments for finger-printing algal types in the water column. Recent additions include zeaxanthin, ascribed as a proposed marker for cyanobacteria (Guillard et al. 1985), alloxanthin, a marker for cryptomonads (Gieskes \& Kraay 1983), and prasinoxanthin, a marker for particular prasinophytes (Foss et al. 1984)
Fucoxanthin (Fig. 1) is confined in the phytoplankton to diatoms, prymnesiophytes, raphidophytes and chrysophytes (Jeffrey \& Vesk 1981, Stauber \& Jeffrey unpubl.). 19'-hexanoyloxyfucoxanthin is the major carotenoid of the coccolithophorid Emiliania (Coccolithus) huxleyi (Arpin et al. 1976) and was also ascribed to natural blooms of the colonial prymnesiophyte Crymbellus aureus (Gieskes \& Kraay, 1986a). Several dinoflagellates (e.g. Gyrodinium aureolum; Bjørnland \& Tangen 1979, Tangen \& Bjørnland 1981) which contain fucoxanthin and 19'-hexanoyloxyfucoxanthin may contain prymnesiophycean endosymbionts (Bjørnland et al. 1984). Recently, a new fucoxanthin derivative from a Norwegian isolate of Pelagococcus (Coc. min., Chrysophyceae) was unequivocally characterized as 19'-butanoyloxyfucoxanthin (Bjørnland et al. 1985). The full paper on this pigment has yet to be published. A similar pigment was

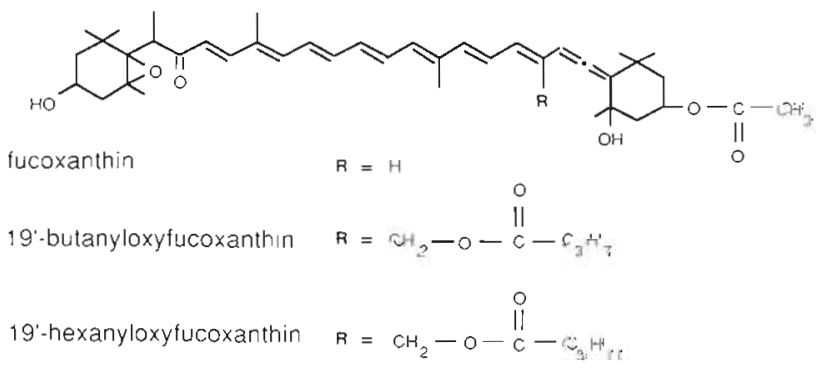

Fig. 1. Chemical structures of fucoxanthin, 19'-butanoyloxyfucoxanthin and 19'-hexanoyloxyfucoxanthin 
reported from other strains of Pelagococcus subviridis (Lewin et al. 1977, Vesk \& Jeffrey 1987), and is referred to here as a $19^{\prime}$-butanoyloxyfucoxanthin-like pigment.

Sucrose TLC was originally used to separate fucoxanthin and the 19'-butanoyloxyfucoxanthin-like pigment from Pelagococcus subviridis (Lewin et al. 1977). In the present work, cellulose TLC (Jeffrey 1981) was used to separate mixtures of fucoxanthin (from Pavlova luthen) and 19'-hexanoyloxyfucoxanthin (from Emiliania huxleyl). However, neither TLC system resolved the $19^{\prime}$-hexanoyloxyfucoxanthin from the $19^{\prime}$ butanoyloxyfucoxanthin-like pigment. Therefore an HPTLC (high-performance thin-layer chromatography) method (Vesk \& Jeffrey 1987) and the HPLC technique of Wright \& Shearer (1984) were both used to separate all 3 fucoxanthin pigments. The present work reports the use of both methods in cultured microalgae and phytoplankton field samples from Antarctic waters.

\section{MATERIALS AND METHODS}

Algal cultures. The cultures used were from the CSIRO Algal Culture Collection (Jeffrey 1980). Pavlova lutheri (CSIRO Culture Code CS-23) and Emiliania huxleyi (CS-57; Clone BT6 from Dr R. R. L. Guillard) were used as source material for standard fucoxanthin (Berger et al. 1977) and standard 19'-hexanoyloxyfucoxanthin (Arpin et al. 1976) respectively. Pelagococcus subviridis (East Australian Current strain; CS99) was used as the source of the 19'-butanoyloxyfucoxanthin-like pigment (Vesk \& Jeffrey 1987). These cultures were grown in $125 \mathrm{ml}$ Erlenmeyer flasks at $17.5^{\circ} \mathrm{C}$ in $40 \mu \mathrm{E} \mathrm{m}^{-2} \mathrm{~s}^{-1}$ white fluorescent light (Phillips Daylight tubes) on 12:12 h light: dark cycles in medium $\mathrm{f}_{2}$ (Guillard \& Ryther 1962). Light intensities were measured with a Biospherical Optics light meter. Three strains of Phaeocystis pouchetii (one isolated by J. L. Stauber in 1981 from the East Australian Current [CS165], one isolated by P. Thomas from Prydz Bay, Antarctica in 1985, and one isolated by S. I. Blackburn from Antarctic waters) were grown in $\mathrm{G}_{5}$ medium (Loeblich \& Smith 1968) under the same conditions. Both strains on Antarctic $P$. pouchetii were grown at $5^{\circ} \mathrm{C}$. For larger volumes, 1 to $10 \mathrm{l}$ cultures were either aerated, or shaken on an orbital shaker at 100 cycles min $^{-1}$, in Erlenmeyer flasks. None of the cultures used in this study were completely axenic.

Collection of phytoplankton field samples. Samples were collected from the MV Nella Dan every $1^{\circ}$ latitude from $60^{\circ} \mathrm{S}$ to the Antarctic coast, along 7 north-south transects between $58^{\circ}$ and $93^{\circ} \mathrm{E}$ longitude made during January 1985 as part of the Second International BIOMASS Experiment, Phase II (SIBEX II; Wright 1987). A
General Oceanics rosette sampler equipped with twelve 51 Niskin bottles was used to collect water samples from $0,10,25,35,50,75,100$ and $200 \mathrm{~m}$ depth. Between 2 and 41 of each sample were filtered for pigment analysis.

Pigments: algal cultures. Cells were harvested at the end of log phase by centrifuging either in a plankton centrifuge at $8000 \times \mathrm{g}$ (large volumes) or in a bench centrifuge at $2000 \times \mathrm{g}$ for 3 to $5 \mathrm{~min}$ (small volumes). Pigments were extracted from the cell pellet in $100 \%$ acetone (except Pelagococcus subviridis, which required freezing in ether/dry ice mixtures before acetone extraction; Vesk \& Jeffrey 1987).

For determination of chlorophylls $a$ and $c$, spectrophotometric analyses of acetone extracts were carried out using the appropriate equations of Jeffrey \& Humphrey (1975). Cell counts of the original cultures were made using a haemocytometer.

For TLC, pigments were transferred from acetone to peroxide-free diethyl ether by adding an equal volume of ether to the acetone extract and gently mixing with 20 volumes of cold $\left(5^{\circ} \mathrm{C}\right) 5 \% \mathrm{NaCl}$ solution. The pigments migrated to the ether hyperphase, which was collected, concentrated under a stream of $\mathrm{N}_{2}$, dried with a little solid $\mathrm{NaCl}$, and stored at $-15^{\circ} \mathrm{C}$ until use.

Pigments: phytoplankton field samples. Samples were filtered under slight vacuum onto Whatman GF/F filters ( $47 \mathrm{~mm}$ diameter). As magnesium carbonate can bind pheophytins and chlorophyllides (Daley et al. 1973), it was not used as a filter aid. The filters were immediately frozen in liquid nitrogen until ready for analysis.

The frozen filters were cut into pieces of approximately $5 \mathrm{~mm}$ diameter, sonicated in $4 \mathrm{ml}$ methanol (30 s at $50 \mathrm{~W}$ ) using a Braun Labsonic 1510 sonicator equipped with a $4 \mathrm{~mm}$ diameter needle probe and filtered using the centrifugal system described in Wright \& Shearer (1984). Methanol was used as an extraction solvent for HPLC because acetone caused peak spreading. The filter debris was washed with $0.5 \mathrm{ml}$ methanol and recentrifuged. The combined extract was filtered through a Millex-SR filter unit (0.5 um pore-size, Millipore Corp.), and chromatographed immediately. No significant allomerization of chlorophylls occurred in the 10 min required for extraction

High-performance thin-layer chromatography. Because the cellulose TLC plate (Jeffrey 1981) was unable to separate all the fucoxanthin pigments, a 1 dimensional reverse-phase HPTLC plate was used, which successfully separated the 3 pigments. The system comprised a Merck RP-8 bonded silica plate, developed for $30 \mathrm{~min}$ with methanol: water $=9: 1(\mathrm{~V} / \mathrm{V})$ (Vesk \& Jeffrey 1987).

High-performance liquid chromatography. Samples 
of $250 \mu \mathrm{l}$ of extract were injected directly into a Waters Associates liquid chromatograph. Two RCM-100 radial compression modules containing Rad-Pak A cartridges ( $5 \mu \mathrm{m}$ particle size, octadecyl silicae) were used in series, protected by a precolumn filter and an RCSS Guard-Pak. The pigments were eluted using a linear gradient from 90:10 acetonitrile:water $(\mathrm{v} / \mathrm{v})$ to ethyl acetate over $20 \mathrm{~min}$ at $2 \mathrm{ml} \mathrm{min}^{-1}$. They were detected by the sum of absorbances at 405 and $436 \mathrm{~nm}$ (Wright \& Shearer 1984), and integrated using a Waters Data Module. For small peaks, where the signal-to-noise ratio was low, the data module was found to be inaccurate, so these peaks were measured manually and converted to pigment abundance using individual calibration curves based on extinction coefficients of $160 \mathrm{l} \mathrm{g}^{-1} \mathrm{~cm}^{-1}$ (at $452 \mathrm{~nm}$; solvent ethanol) for fucoxanthin and derivatives (Jensen 1966), $250 \mathrm{l} \mathrm{g}^{-1} \mathrm{~cm}^{-1}$ (at $450 \mathrm{~nm}$; solvent ethanol) for carotene, diadinoxanthin and diatoxanthin (Goodwin 1955), and $88.15 \mathrm{lg}^{-1} \mathrm{~cm}^{-1}$ (at $663 \mathrm{~nm}$; solvent acetone for chlorophyll a (Jeffrey \& Humphrey 1975). As there was insufficient material in most phytoplankton field extracts to obtain absorption spectra, the pigments could be identified initially only by comparison of retention times with known standards. However, after all field samples were analysed, peak identities were confirmed by pooling selected samples into one concentrate (referred to here as Antarctic concentrate), which was rechromatographed. Absorption spectra for initial identification were then taken during elution, using a Hewlett-Packard 8450A spectrophotometer.

Visible absorption spectra. For precise absorption spectra, purified samples from cultures were isolated on TLC systems (reverse-phase RP-8 plate, or washed cellulose (Jeffrey 1981) and examined either in a Cary Model 14 or a Shimadzu Model RPI recording spectrophotometer.

It should be noted that where only chromatographic and visible absorption spectroscopy data, and not full chemical characterization, are available, the pigment should be identified by the suffix '-like' (SCOR Working Group 77 on Photosynthetic Pigments, unpublished recommendation). This has been followed in the present paper, e.g. only fucoxanthin from Pavlova lutheri and 19'-hexanoyloxyfucoxanthin from Emiliania huxleyi have been fully chemically characterized (Arpin et al. 1976, Berger et al. 1977).

\section{RESULTS}

The reverse-phase RP- 8 HPTLC plate separated the 3 fucoxanthin pigments - fucoxanthin $\left(R_{F}\right.$ value 0.43$)$, 19 '-hexanoyloxyfucoxanthin $\left(R_{F}\right.$ value 0.40$)$ and the $19^{\prime}$-butanoyloxyfucoxanthin-like pigment $\left(R_{F}\right.$ value
0.48) - from extracts of cultures of Pavlova lutheri, Emiliania huxleyi and Pelagococcus subviridis and mixtures of these (Fig. 2A, B, C, D). All 3 pigments were found in the East Australian Current strain and 2 Antarctic strains of Phaecystis pouchetii, although the proportion of the fucoxanthin pigments was variable (Fig. 2E, F, G). The Antarctic concentrate also contained the 3 fucoxanthin pigments (Fig. $2 \mathrm{H}$ ).

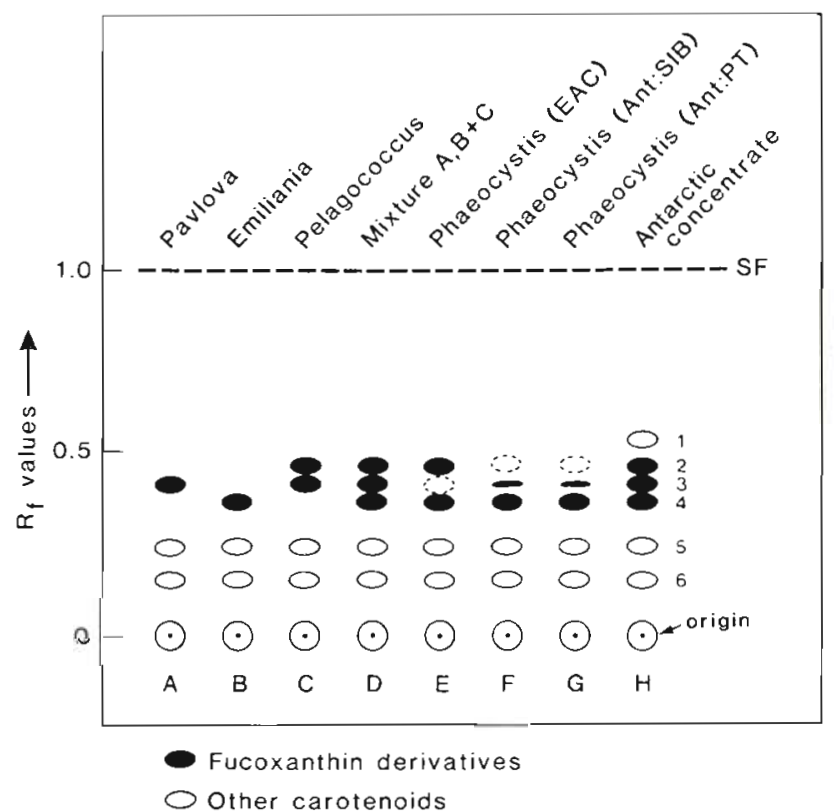

Fig. 2. Separation of major carotenoids from various algal species and the Antarctic concentrate on the reverse-phase bonded-silica HPTLC plate (Merck, RP-8). (A) Pavlova lutheri; (B) Emiliania huxleyi; (C) Pelagococcus subviridis; (D) mixture of $A, B$ \& $C$; (E, F, G) Phaeocystis pouchetii: East Australian Current strain (EAC), and Antarctic strains (S. I. Blackburn [Ant:SIB] and P. Thomas [Ant:PT] respectively); (H) Antarctic concentrate. 1: peridinin (red): 2: 19'-butanoyloxyfucoxanthin-like (yellow-orange); 3 : fucoxanthin (red-orange); $4: 19^{\prime}$ hexanoyloxyfucoxanthin (yellow-orange); 5: diadinoxanthin (yellow); 6: diatoxanthin (pale orange)

The visible absorption spectra of these pigments in different solvents are given in Fig. 3 (no quantitative relations between the solvents is intended) and absorption maxima and band ratios of the 3 fucoxanthin pigments from different algal sources are given in Table 1. The spectra of $19^{\prime}$-hexanoyloxyfucoxanthin and the 19'-butanoyloxyfucoxanthin-like pigment differed from that of fucoxanthin by having a pronounced minimum between Peaks II and III (sensu Ke et al. 1970), whereas in fucoxanthin this minimum was absent, Peak III being a shoulder. The III:II band ratios for the $19^{\prime}$-hexanoyloxyfucoxanthin and $19^{\prime}$-butanoyloxyfucoxanthin-like pigment differed depending on algal source. We ascribe these variations to solvent effects caused by slight differences in the concentration 

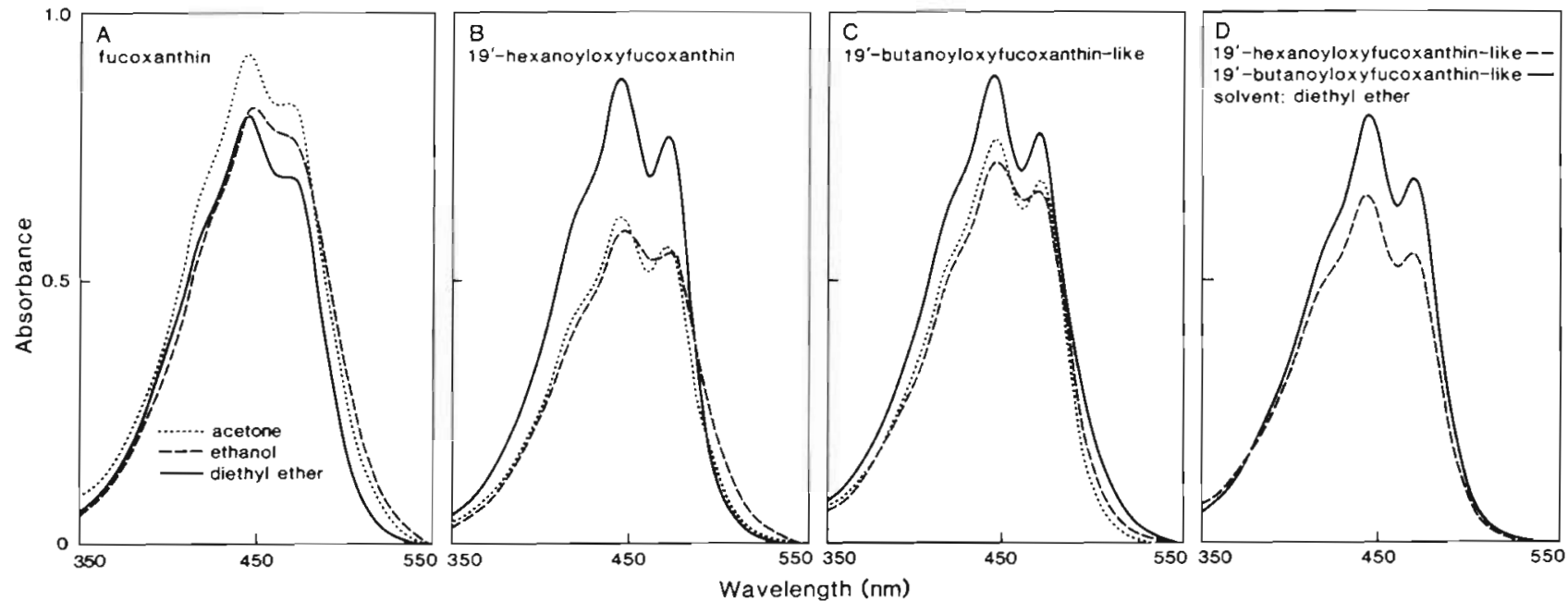

Fig. 3. Visible absorption spectra of fucoxanthin pigments in acetone, ethanol and diethyl ether. (A) Fucoxanthin from $P a v l o v a$ lutheri; (B) 19'-hexanoyloxyfucoxanthin from Emiliania huxleyi; (C) 19'-butanoyloxyfucoxanthin-like pigment from Pelagococcus subviridis; (D) the 19'-hexanoyloxyfucoxanthin-like and 19'-butanoyloxyfucoxanthin-like pigments from Phaeocystis pouchetii in diethyl ether. (Band II is the $450 \mathrm{~nm}$ peak and Band III is the $470 \mathrm{~nm}$ peak referred to in Table 1; Ke et al. 1970).

of water and other cell components extracted with the pigments.

The separation of the 3 fucoxanthin pigments on the HPLC system of Wright \& Shearer (1984) is shown for the first time in Fig. 4. The algal extracts and Antarctic concentrate were the same as those used on the HPTLC system (Fig. 2). HPLC confirmed the resolution of the major fucoxanthin derivatives obtained with the HPTLC plate, but the extra sensitivity also revealed the presence of minor components, including the cis-isomers of fucoxanthin and $19^{\prime}$-hexanoyloxyfucoxanthin, and an unknown carotenoid pigment, which eluted just before fucoxanthin.

Quantitative analyses of the major pigments in Pavlova lutheri, Emiliania huxleyi, Phaeocystis pouchetii and the Antarctic samples are shown in Table 2, and the ratios of the 3 fucoxanthin pigments are given in Table 3.

Table 1. Absorption maxima (nm) and band ratios of fucoxanthin pigments in various solvents

\begin{tabular}{|c|c|c|c|c|c|c|}
\hline \multirow[t]{2}{*}{ Alga } & \multirow{2}{*}{$\begin{array}{l}\text { CSIRO Culture } \\
\text { Code No. }\end{array}$} & \multirow[t]{2}{*}{ Pigment } & \multirow[t]{2}{*}{ Solvent } & \multicolumn{2}{|c|}{ Maxima } & \multirow{2}{*}{$\begin{array}{l}\text { Band ratios } \\
\text { III:II }(\%)\end{array}$} \\
\hline & & & & Band II & Band III & \\
\hline Pavlova lutheri & CS.23 & Fucoxanthin & $\begin{array}{l}\text { Ethanol } \\
\text { Acetone } \\
\text { Diethyl ether }\end{array}$ & $\begin{array}{l}448 \\
446 \\
446\end{array}$ & $\begin{array}{r}\sim 470 \\
470 \\
470\end{array}$ & $\begin{array}{l}0 \\
3.3 \\
3.3\end{array}$ \\
\hline Emiliania huxleyi & CS.57 & $\begin{array}{l}19^{\prime} \text {-hexanoyloxy } \\
\text { fucoxanthin }\end{array}$ & $\begin{array}{l}\text { Ethanol } \\
\text { Acetone } \\
\text { Diethyl ether }\end{array}$ & $\begin{array}{l}447 \\
445 \\
444\end{array}$ & $\begin{array}{l}471 \\
471 \\
470\end{array}$ & $\begin{array}{l}25.0 \\
43.7 \\
44.8\end{array}$ \\
\hline Pelagococcus subviridis & $\operatorname{CS}-99$ & $\begin{array}{l}19^{\prime} \text {-butanoyloxy- } \\
\text { fucoxanthin-like }\end{array}$ & $\begin{array}{l}\text { Ethanol } \\
\text { Acetone } \\
\text { Diethyl ether }\end{array}$ & $\begin{array}{l}446 \\
445 \\
444\end{array}$ & $\begin{array}{l}470 \\
471 \\
470\end{array}$ & $\begin{array}{l}18 \\
40 \\
39\end{array}$ \\
\hline \multirow[t]{2}{*}{ Phaeocystis pouchetii } & \multirow[t]{2}{*}{ CS-165 } & $\begin{array}{l}19^{\prime} \text {-hexanoyloxy- } \\
\text { fucoxanthin-like" }\end{array}$ & $\begin{array}{l}\text { Ethanol } \\
\text { Acetone } \\
\text { Diethyl ether }\end{array}$ & $\begin{array}{l}446 \\
444 \\
444\end{array}$ & $\begin{array}{l}470 \\
470 \\
470\end{array}$ & $\begin{array}{l}20.7 \\
35 \\
34\end{array}$ \\
\hline & & $\begin{array}{l}19^{\prime} \text {-butanoyloxy- } \\
\text { fucoxanthin-like. }\end{array}$ & $\begin{array}{l}\text { Ethanol } \\
\text { Acetone } \\
\text { Diethyl ether }\end{array}$ & $\begin{array}{l}447 \\
445 \\
444\end{array}$ & $\begin{array}{l}470 \\
469 \\
470\end{array}$ & $\begin{array}{l}11.7 \\
20 \\
26.6\end{array}$ \\
\hline \multicolumn{7}{|c|}{$\begin{array}{l}\text { - For a full analysis of } P \text { subviridis pigments ( } 2 \text { strains), see Vesk \& Jeffrey (1987) } \\
\text { Where only chromatographic and spectral data are available, and not full chemical characterization, the suffix-'like' is } \\
\text { added (SCOR Working Group 77, unpubl. recommendation) }\end{array}$} \\
\hline
\end{tabular}



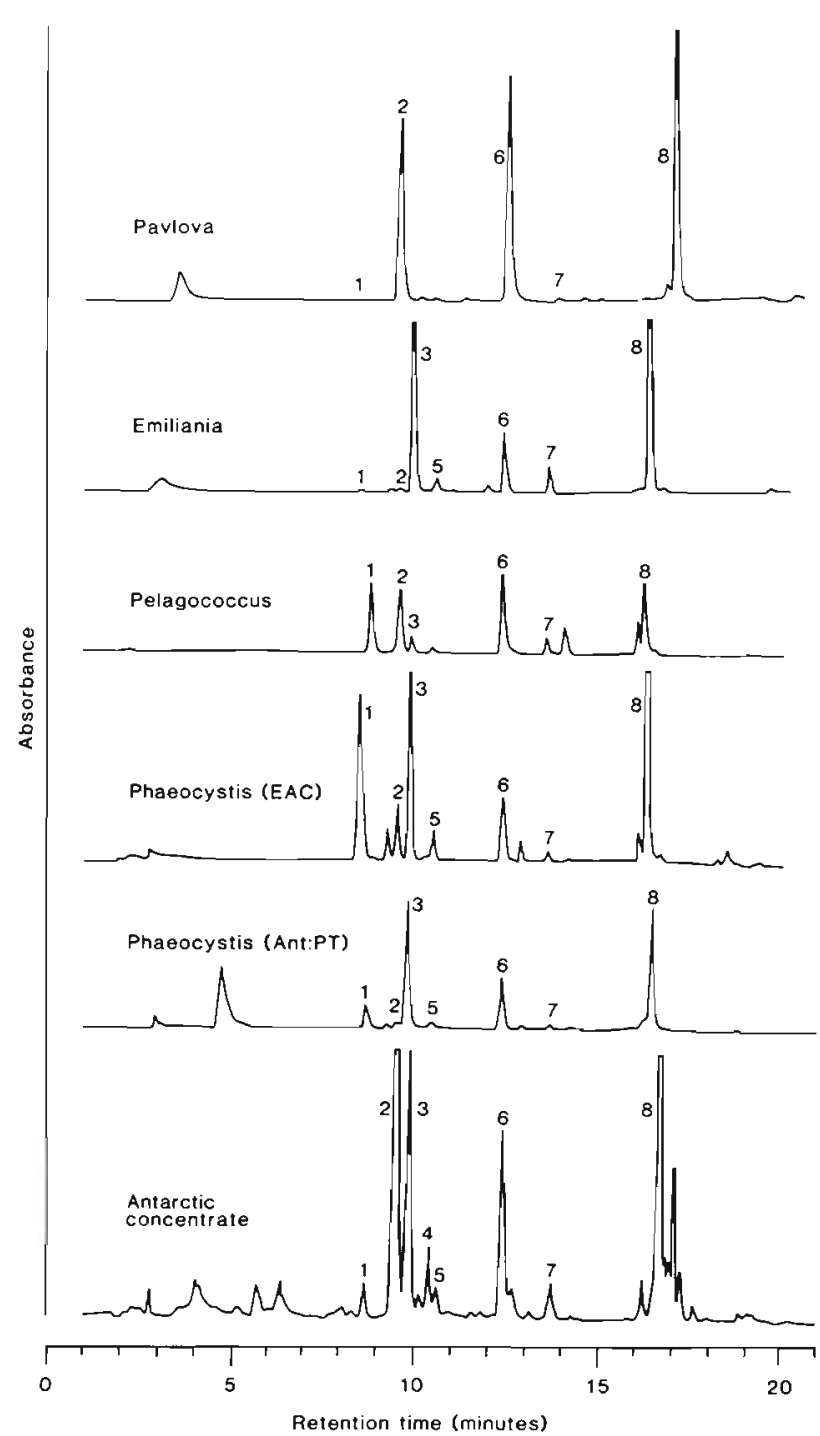

Fig, 4. HPLC traces of pigment separations of the algae shown in Fig. 2 and the Antarctic concentrate. Pigment fractions are: $119^{\prime}$-butanoyloxyfucoxanthin-like pigment; 2 fucoxanthin; 3 $19^{\prime}$-hexanoyloxyfucoxanthin; 4 cis-fucoxanthin; 5 cis $19^{\prime}$-hexanoyloxyfucoxanthin; 6 diadinoxanthin; 7 diatoxanthin; 8 chlorophyll a. Retention times as shown. It should be noted that Peak 3 in both Phaeocystis pouchetii isolated should be referred to as ' 19 '-hexanoyloxyfucoxanthin-like', until chemical characterization has been carried out

That the pigments in the Antarctic concentrate were identical with the fucoxanthin derivatives in the various algal cultures was confirmed by absorption spectroscopy and by co-chromatography in the HPLC and HPTLC systems. In addition, allene groups, which are present in fucoxanthin and its derivatives, were detected in the fucoxanthin and 19'-hexanoyloxyfucoxanthin fractions isolated from the Antarctic samples by an absorption peak at $1929 \mathrm{~nm}$, using infrared spectroscopy. Colourless contaminants (presumably lipids) prevented full characterization of these pigments and completely swamped the tiny amount of the 19'butanoyloxyfucoxanthin-like pigment available from the field samples, for which no infrared spectra were obtained at this time.

Other minor and trace pigments were also present in the cultures and the Antarctic concentrate (Wright \& Shearer 1984, Vesk \& Jeffrey 1987), but these will be discussed fully elsewhere (Wright 1987).

\section{DISCUSSION}

\section{Algal cultures}

The present work confirms the presence of fucoxanthin alone (free from traces of other fucoxanthin pigments) in Pavlova lutheri, previously examined by Berger et al. (1977). Emiliania huxleyi, in addition to containing the dominant 19'-hexanoyloxyfucoxanthin (Arpin et al. 1976), also contained small amounts of fucoxanthin and the $19^{\prime}$-butanoyloxyfucoxanthin-like pigment (Tables 2 \& 3). Pelagococcus subviridis contained fucoxanthin and the 19'-butanoyloxyfucoxanthin-like pigment as the major carotenoids (Vesk \& Jeffrey 1987), but HPLC also revealed the presence of small amounts of $19^{\prime}$-hexanoyloxyfucoxanthin (Fig. 2).

The identity of the fucoxanthin and $19^{\prime}$-hexanoyloxyfucoxanthin was confirmed by using pigment standards from well-characterized sources, but the identity of the 19'-butanoyloxyfucoxanthin-like pigment from Pelagococcus subviridis is still unclear. True 19'butanoyloxyfucoxanthin was chemically identified together with fucoxanthin in the Norwegian isolate of a Pelagococcus-like strain (Coc. min.) by Bjørnland et al. (1984), although the full data, including visible spectra and chromatographic systems, have yet to be published. The fucoxanthin derivative present in both our strains of Pelagococcus (Vesk \& Jeffrey 1987) was chromatographically different from $19^{\prime}$-hexanoyloxyfucoxanthin, yet spectrally similar (Fig. 3), and we initially assumed it to be the $19^{\prime}$-butanoyloxyfucoxanthin of Bjornland et al. (1984). However, in both our HPLC and HPTLC systems, where the chromatographic mobility of an homologous series is related to the length of the hydrophobic substituent, the sequence of the 3 fucoxanthin pigments was different from that we would expect if this pigment were 'true' $19^{\prime}$ 'butanoyloxyfucoxanthin. On the basis of chemical structures (Fig. 1), 19'-butanoyloxyfucoxanthin should be intermediate in polarity between fucoxanthin and $19^{\prime}$-hexanoyloxyfucoxanthin, but in both our chromatographic systems (HPLC and HPTLC) it appeared to be more polar than both (Fig. $2 \& 3$ ). The possibility remains that our pigment either has an additional polar group (e.g. hydroxyl) or has lost the methyl ester of the 
Table 2. Quantitative analyses of major pigments in Pavlova Iutheri, Emiliania huxleyi, Phaeocystis pouchetii, Pelagococcus subviridis and the Antarctic concentrate, from HPLC analysis for carotenoids and spectrophotometric analysis (Jeffrey \& Humphrey 1975) for chlorophylls a and c. Minor carotenoids (Fig. 4) are not included

\begin{tabular}{|c|c|c|c|c|c|}
\hline \multirow[t]{2}{*}{ Pigment } & \multicolumn{5}{|c|}{ Algal sample } \\
\hline & $\begin{array}{c}\text { P. Iutheri } \\
\mu \mathrm{g}\left(10^{8} \text { cells }\right)^{-1}\end{array}$ & $\begin{array}{c}\text { E. huxleyi } \\
\mu \mathrm{g}\left(10^{8} \text { cells }\right)^{-1}\end{array}$ & $\begin{array}{c}\text { P. pouchetii } \\
\mu \mathrm{g}\left(10^{8} \mathrm{cells}\right)^{-1}\end{array}$ & $\begin{array}{c}\text { P. subviridis } \\
\mu \mathrm{g}\left(10^{8} \text { cells }\right)^{-1}\end{array}$ & $\begin{array}{c}\text { Antarctic } \\
\text { concentrate } \mu g \mathrm{l}^{-1}\end{array}$ \\
\hline Chlorophyll a & 17.0 & 31.0 & 9.5 & 2.35 & 0.39 \\
\hline Chlorophyll $C$ & 2.0 & 8.0 & 4.0 & 0.55 & 0.26 \\
\hline$\beta, \beta$-carotene & 0.2 & 0.39 & 0.06 & 0.02 & 0.01 \\
\hline Fucoxanthin & 5.4 & 0.41 & 0.76 & 1.2 & 0.36 \\
\hline $19^{\prime}$-hexanoyloxyfucoxanthin & 0 & 31.3 & 2.7 & 0.26 & 0.24 \\
\hline $19^{\prime}$-butanoyloxyfucoxanthin-like & 0 & 0.27 & 2.7 & 1.2 & 0.03 \\
\hline Diadinoxanthin & 4.1 & 4.3 & 0.57 & 1.0 & 0.12 \\
\hline Diatoxanthin & 0.1 & 2.4 & 0.13 & 0.42 & 0.03 \\
\hline
\end{tabular}

Table 3. Ratios of fucoxanthin pigments from HPLC analysis of algal cultures and Antarctic water samples

\begin{tabular}{|c|c|c|c|}
\hline \multirow[t]{2}{*}{ Alga or phytoplankton sample } & \multicolumn{3}{|c|}{ Pigment ratios } \\
\hline & Fucoxanthin & $\begin{array}{l}19^{\prime} \text {-hexanoyloxy- } \\
\text { fucoxanthin }\end{array}$ & $\begin{array}{l}19^{\prime} \text {-butanoyloxy- } \\
\text { fucoxanthin-like pigment }\end{array}$ \\
\hline Pavlova lutheri & 1 & 0 & 0 \\
\hline Emiliania huxleyi & 1 & 76 & 0.6 \\
\hline Phaeocystis pouchetii (EA Current) & 1 & 3.5 & 3.5 \\
\hline Phaeocystis pouchetii (Antarctic) ${ }^{*}$ & 1 & 7 & 0.7 \\
\hline Phaeocystis pouchetii (Antarctic) ${ }^{*}$ & 1 & 21.7 & 0.3 \\
\hline $\begin{array}{l}\text { Phaeocystis pouchetii (Antarctic) } \\
\text { (senescent culture) }\end{array}$ & 0 & 1 & 0.5 \\
\hline Antarctic concentrate & 1 & 0.66 & 0.08 \\
\hline Average of 40 Antarctic water samples & 1 & $\begin{array}{c}0.53 \\
(0.15 \text { to } 1.98)\end{array}$ & $\begin{array}{c}0.04 \\
(0.005 \text { to } 0.16)\end{array}$ \\
\hline $\begin{array}{l}\therefore \text { P. Thomas isolate } \\
\therefore \text { S. Blackburn isolate }\end{array}$ & & & \\
\hline
\end{tabular}

native fucoxanthin. On the basis of chromatographic properties, this pigment is probably identical to the unknown fucoxanthin derivative found by Gieskes \& Kraay (1986b) in the tropical Atlantic. The chemical structure of this $19^{\prime}$-butanoyloxyfucoxanthin-like pigment from our strains of Pelagococcus subviridis is currently under investigation.

Cultured strains of Phaeocystis pouchetii examined in the present work contained all 3 fucoxanthin pigments, with the pigment chromatographically and spectrally identical to $19^{\prime}$-hexanoyloxyfucoxanthin dominant in each strain. The 19'-butanoyloxyfucoxanthin-like pigment was co-dominant in the East Australian Current strain, but was present as a minor component with fucoxanthin in both Antarctic strains. Significant differences in the proportions of these pigments were observed between strains and age of culture (Table 3). These results are in agreement with those of Dr S. Liaaen-Jensen, who found both $19^{\prime}$-hexanoyloxyfucoxanthin and $19^{\prime}$-butanoyloxyfucoxanthin in cultured Phaeocystis pouchetii (pers. comm.). Our results are in apparent contradiction to those of Gieskes \& Kraay (1986a), who stated that field populations of Phaeocystis pouchetii do not contain $19^{\prime}$-hexanoyloxyfucoxanthin, but without further details it cannot be determined whether culture, extractions methods or strain differences would explain the conflicting observations.

\section{Antarctic water samples}

Extensive use of the HPLC method during the SIBEX II experiment in Antarctic waters allowed distribution of the 3 fucoxanthin pigments (integrated for the top $100 \mathrm{~m}$ ) to be determined over a wide area (Wright 1987). Significant differences in the abundances of the 3 pigments were noted. The range of values for fucoxanthin was 2.2 to $247 \mathrm{mg} \mathrm{m}^{-2}$, compared to 5.1 to $323 \mathrm{mg} \mathrm{m}^{-2}$ for chlorophyll a, 2.4 to $83 \mathrm{mg} \mathrm{m}^{-2}$ for $19^{\prime}-$ 
hexanoyloxyfucoxanthin and 0.06 to 3.2 for the $19^{\prime}$ butanoyloxyfucoxanthin-like pigment. At some stations $19^{\prime}$-hexanoyloxyfucoxanthin was more abundant than fucoxanthin. 19'-hexanoyloxyfucocanthin has recently been reported as present in the Southern Ocean (Gieskes \& Elbrächter 1986), in the tropical Atlantic (Gieskes \& Kraay 1986b) and dominant in the North Sea during a bloom of the colonial prymnesiophyte Corymbellus aureus (Gieske \& Kraay 1986a), during which it reached 7 times the concentration of fucoxanthin.

The origin of the fucoxanthin derivatives in Antarctic waters is not yet clear, since very little is known of the taxonomic distribution of these newly recognized pigments. Size fractionation of the Antarctic phytoplankton samples showed that both the 19'-hexanoyloxyfucoxanthin and $19^{\prime}$-butanoyloxyfucoxanthin-like pigments were significantly concentrated in the $<5 \mu \mathrm{m}$ fraction, with most fucoxanthin being found in the $>5 \mu \mathrm{m}$ fraction (Wright 1987), the latter probably originating from diatoms (Stauber \& Jeffrey unpubl.). One source of the fucoxanthin derivatives is likely to be the prymnesiophyte Phaeocystis pouchetii, which was widespread in the study area during SIBEX II (Marchant \& Wright unpubl.). Other sources of fucoxanthin derivatives are also likely. A significant number of nanoplanktonic flagellates ( 2 to $20 \mu \mathrm{m}$ ) were observed in Antarctic water samples during this cruise (Marchant \& Wright unpubl.), characterization of which has not yet been completed. Booth \& Marchant (1987) have described 7 new species from Antarctic water phytoplankton within the newly described order Parmales in the Chrysophyceae. Elucidation of the pigment composition of the Parmales and other unidentified forms awaits successful isolation and culture. Pelagococcus subviridis, another minute planktonic chrysophyte (2 to $3 \mu \mathrm{m})$, is widely distributed in the North Pacific Ocean (Lewin et al. 1977), the East Australian Current (Vesk \& Jeffrey 1987) and Norwegian waters (Throndsen \& Kristiansen 1985) and can reach concentrations of $10^{6}$ to $10^{7}$ cells $1^{-1}$. Given the wide range of habitats in which it has been found, it is quite possible that $P$. subviridis and related organisms could be present in Antarctic waters as well, and contribute to the $19^{\prime}$ butanoyloxyfucoxanthin-like distributions.

A few dinoflagellate genera are known to contain combinations of fucoxanthin, 19' -butanoyloxyfucoxanthin and $19^{\prime}$-hexanoyloxyfucoxanthin. However, dinoflagellates are unlikely to have been a major source of fucoxanthin pigments in these Antarctic water samples. Although Gymnodinium spp. and other dinoflagellates were present in the study area, they were never abundant (Marchant \& Wright unpubl.).
Acknowledgements. We thank Mrs J. L. Stauber for isolating the East Australian Current strains of Phaeocystis pouchetii and Pelagococcus subviridis, Mr P. Thomas and Dr S. I. Blackburn for the 2 Antarctic strains of Phaeocystis pouchetii, Dr S. I. Blackburn for growing the cultures used in the present work, Mr D. Le for the cell counts, Mr J. D. Shearer for assistance with the Southern Ocean field sampling, Mrs T. Glaesner for HPLC assistance, and Dr N. Davies (University of Tasmania) for the infrared spectrometry. We are indebted to Dr G. M. Hallegraeff and Dr H. Marchant for helpful comments on the manuscricpt.

\section{LITERATURE CITED}

Arpin, N., Svec, W. A., Liaaen-Jensen, S. (1976). New fucoxanthin-related carotenoids from Coccolithus huxleyi. Phytochemistry 15: 529-532

Berger, R., Liaaen-Jensen, S., McAlister, V., Guillard, R. R. L. (1977). Carotenoids of Prymnesiophyceae (Haptophyceae). Biochem. Syst. Ecol. 5: 71-75

Bjornland, T., Pennington, F., Haxo, F. T., Liaaen-Jensen, S. (1984). Carotenoids of Crysophyceae and Dinophyceae. Abs. 7 th Int. IUPAC Symposium on Carotenoids, Munich, p. 26

Bjørnland, T., Tangen, K. (1979). Pigmentation and morphology of a marine Gyrodinium (Dinophyceae) with a major carotenoid different from peridinin and fucoxanthin. J. Phycol. 15: $457-463$

Booth, B. C., Marchant, H. J. (1987). Parmales, a new order of marine chrysophytes with descriptions of 3 new genera and 7 new species. J. Phycol. (in press)

Daley, R. J., Gray, C. B. J., Brown, S. R. (1973). A quantitative, semiroutine method for determining algal and sedimentary chlorophyll derivatives. J. Fish. Res. Bd Can. 30: 345-356

Foss, P., Guillard, R. R. L., Liaaen-Jensen, S. (1984). Prasinoxanthin - a chemosystematic marker for algae. Phytochem. 23: $1629-1633$

Gieskes, W. W. C., Elbrächter, M. (1986). Abundance of nanoplankton-size chlorophyll-containing particles caused by diatom disruption in surface waters of the Southern Ocean (Antarctic Peninsula region). Neth. J. Sea Res. 20: 291-303

Gieskes, W. W. C., Kraay, G. W (1983). Dominance of Cryptophyceae during the phytoplankton spring bloom in the central North Sea detected by HPLC analysis of pigments. Mar. Biol. 75: 179-185

Gieskes, W. W. C., Kraay, G. W (1986a). Analysis of phytoplankton pigments by HPLC before, during and after mass occurrence of the microflagellate Corymbellus aureus during the spring bloom in the open northern North Sea in 1983. Mar. Biol. 92: 45-52

Gieskes, W. W. C., Kraay, G. W. (1986b). Floristic and physiological differences between the shallow and the deep nanophytoplankton community in the euphotic zone of the open tropical Atlantic revealed by HPLC analysis of pigments. Mar. Biol. 91: 567-576

Goodwin, T. W. (1955). Carotenoids. In: Peach, K., Tracey, M. (ed.) Modern methods in plant analysis, Vol. 3. SpringerVerlag, Heidelberg, p. 272-311

Guillard, R. R. L., Murphy, L. S., Foss, P., Liaaen-Jensen, S. (1985). Synechococcus spp. as likely zeaxanthin-dominant ultraphytoplankton in the North Atlantic. Limnol. Oceanogr. 30: 412-414

Guillard, R. R. L., Ryther, J. H. (1962). Studies of marine plankton diatoms. I. Cyclotella nana Hustedt and Detonula confervacea (Cleve) Gran. Can. J. Microbiol. 8: 229-239 
Hallegraeff, G. M. (1981). Seasonal study of phytoplankton pigments and species at a coastal station off Sydney: importance of diatoms and the nanoplankton. Mar Biol. 61: $107-118$

Hallegraeff, G. M., Jeffrey, S. W (1984). Tropical phytoplankton species and pigments of continental shelf waters of North and North-West Australia. Mar Ecol. Prog. Ser. 20: $59-74$

Hallegraeff, G. M., Jeffrey, S. W (1985). Description of new chlorophyll a alteration products in marine phytoplankton. Deep Sea Res. 32: 697-705

Jeffrey, S. W. (1974). Profiles of photosynthetic pigments in the ocean using thin-layer chromatography. Mar. Biol. 26: $101-110$

Jeffrey, S. W. (1976). A report of green algal pigments in the Central North Pacific Ocean. Mar. Biol. 37: 33-37

Jeffrey, S. W. (1980). Cultivating unicellular marine plants. CSIRO (Hobart, Tasmania) Fish and Oceanogr. A. Rep. 1977-1979, p. 22-43

Jeffrey, S. W. (1981). An improved thin-layer chromatographic technique for marine phytoplankton pigments. Limnol. Oceanogr. 26: 191-197

Jeffrey, S. W. Hallegraeff, G. M. (1980). Studies of phytoplankton species and photosynthetic pigments in a warm core eddy of the East Australian Current. I. Summer populations. Mar. Ecol. Prog. Ser. 3: 285-294

Jeffrey, S. W., Hallegraeff, G. M. (1987). Phytoplankton pigments, species and light climate in a complex warm-core eddy of the East Australian Current. Deep Sea Res. 34: in press

Jeffrey, S. W., Humphrey, G. F. (1975). New spectrophotometric equations for determining chlorophylls $a_{1} b, c_{1}$, and $c_{2}$ in higher plants, algae and natural phytoplankton. Biochem. Physiol. Pflanz. 167: 191-194

Jeffrey, S. W., Vesk, M. (1981). The phytoplankton-systematics, morphology and ultrastructure. In: Clayton, M. N., King, R. J. (ed.) Marine botany - an Australasian perspective. Longman-Cheshire, Melbourne, p. 138-179
Jensen, A. (1966). Algal carotenoids. V Iso-fucoxanthinrearrangement product of fucoxanthin. Acta chem. scand. 29: $1728-1730$

Ke, B., Imsgard, F., Kjøsen, H., Liaaen-Jensen, S. (1970). Electronic spectra of carotenoids at $77 \mathrm{~K}$. Biochim. biophys. Acta 210: 139-152

Lewin, J., Norris, R. E., Jeffrey, S. W., Pearson, B. E. (1977). An aberrant chrysophycean alga Pelagococcus subviridis gen nov. et sp. nov. from the North Pacific Ocean. J. Phycol. 13 $259-266$

Loeblich, A. R. III, Smith, V. E. (1968). Chloroplast pigments of the marine dinoflagellate Gyrodinium resplendens. Lipids 3: 5-13

Mantoura, R. F. C., Llewellyn, C. A. (1983). The rapid determination of algal chlorophyll and carotenoid pigments and their breakdown products in natural waters by reversephase high-performance liquid chromatography. Aralytica chim. Acta 151: 297-314

Tangen, K., Bjørnland, T (1981). Observations on pigments and morphology of Gyrodinium aureolum Hulbert, a marine dinoflagellate containing 19'-hexanoyloxyfucoxanthin as the main carotenoid. J. Plankton Res. 3: 389-401

Throndsen, J., Kristiansen, S. (1985). Pelagococcus subviridis Norris as a major component of the nanoplankton at Haltenbanken, Norwegian Sea in July 1982. Abst. Internat. Phycological Congress, p. 160

Vesk, M., Jeffrey, S. W. (1987) Ultrastructure and pigments of two strains of the picoplanktonic algae Pelagococcus subviridis (Chrysophyceae). J. Phycol. 23: 322-336

Wright, S. W., Shearer, J. D. (1984). Rapid extraction and high-performance liquid chromatography of chlorophylls and carotenoids trom marine phytoplankton. J. Chromatog. 294: 281-295

Wright, S. W. (1987). The distribution and abundance of phytoplankton pigments during the SIBEX II cruise, Prydz Bay, Antarctica, 1985. Australian National Antarctic Research Expedition Research Note (in press) 